This document is the accepted manuscript version of the following article:

Shchyrba, A., wäckerlin, C., Nowakowski, J., Nowakowska, S., Björk, J., Fatayer, S., ... Gade, L. H. (2014). Controlling the dimensionality of on-surface coordination polymers via endoor exoligation. Journal of the American Chemical Society, 136(26), 9355-9363.

https://doi .org/10.1021/ja5020103

\title{
Controlling the dimensionality of on-surface coordination polymers via endo- or exo-ligation
}

\author{
Aneliia Shchyrba, ${ }^{* \dagger}$ Christian Wäckerlin,,,\& Jan Nowakowski, ${ }^{\#}$ Sylwia Nowakowska, ${ }^{\dagger}$ Jonas Björk, ${ }^{\$}$ Shadi \\ Fatayer, ${ }^{\dagger}$ Jan Girovsky, ${ }^{\#}$ Thomas Nijs, ${ }^{\dagger}$ Susanne C. Martens, ${ }^{\dagger, \S}$ Armin Kleibert, ${ }^{£}$ Meike Stöhr, Nirmalya Ballav, ${ }^{\ddagger}$ \\ Thomas A. Jung*,\# and Lutz H. Gade*,\$ \\ ${ }^{\dagger}$ Department of Physics, University of Basel, Klingelbergstrasse 82, 4056 Basel, Switzerland \\ \# Laboratory for Micro- and Nanotechnology, Paul Scherrer Institute, 5232 Villigen PSI, Switzerland \\ \$ Department of Physics, Chemistry and Biology, IFM, Linköping University, Linköping 581 83, Sweden \\ ${ }^{£}$ Swiss Light Source at Paul Scherrer Institute, 5232 Villigen PSI, Switzerland \\ " Zernike Institute for Advanced Materials, University of Groningen, Nijenborgh 4, 9747 AG Groningen, The Netherlands \\ * Department of Chemistry, Indian Institute of Science Education and Research, Pune 411008, India \\ $\S$ Anorganisch-Chemisches Institut, Universität Heidelberg, Im Neuenheimer Feld 270, 69120 Heidelberg, Germany
}

\begin{abstract}
The formation of on-surface coordination polymers is controlled by the interplay of chemical reactivity and structure of the building blocks, as well as by the orientating role of the substrate registry. Beyond the pre-determined patterns of structural assembly, the chemical reactivity of the reactants involved may provide alternative pathways in their aggregation. Organic molecules, which are transformed in a surface reaction, may be subsequently trapped via coordination of homo- or_heterometal adatoms, which may also play a role in the molecular transformation itself. The amino-functionalized perylene derivative, 4,9diaminoperylene-quinone-3,10-diimine (DPDI), undergoes specific levels of dehydrogenation $\left(-1 \mathrm{H}_{2}\right.$ or $\left.-3 \mathrm{H}_{2}\right)$ depending on the nature of the present adatoms ( $\mathrm{Fe}, \mathrm{Co}, \mathrm{Ni}$ or $\mathrm{Cu}$, respectively). In this way, the molecule is converted to an endo- or an exo-ligand, possessing a concave or convex arrangement of ligating atoms, which is decisive for the formation of either $1 \mathrm{D}$ or $2 \mathrm{D}$ coordination polymers.
\end{abstract}

\section{INTRODUCTION}

Organic and metal-organic networks ${ }^{1-18}$ generated on metal surfaces have been shown to alter the electronic properties of the substrate and to serve as templates for the formation of host-guest complexes, ${ }^{19-26}$ giving rise to complex forms of aggregation.

The mechanisms of on-surface reactions may differ significantly from those in solution, ${ }^{27}$ thereby creating the opportunity to explore new 'on-surface phenomena'. ${ }^{28}$ Coordination between organic molecular ligands and metal adatoms, ${ }^{12,29-38}$ on one hand, and on-surface coupling and breaking of covalent bonds, ${ }^{18,28,39-58}$ on the other, have both been found to give rise to stable, well-ordered structures. There are thus several levels of chemical transformations and bonding interactions determining the assembly of molecular on-surface structures. Through reaction with surface adatoms, the building block or synthon can be modified prior to coordinative polymerization, as exemplified by the deprotonation of $\mathrm{COOH}$ to the ligating $\mathrm{COO}^{-}$in carboxylatebased surface coordination polymers. ${ }^{35,59-61}$ In previous work, the nature of the metal adatom exhibited only a minor influence on the topology of the 2D layer, ${ }^{62-64}$ which is commonly predicted on the basis of the organic ligand only.
In this work, we demonstrate how two nitrogen-containing functional groups in a polycyclic aromatic architecture undergo modification depending on the specific reactivity of the available metal adatoms. Previously, we reported the formation of a highly stable porous network upon deposition of 4,9-diaminoperylene-quinone-3,10-diimine (DPDI) onto a $\mathrm{Cu}(111)$ surface and subsequent annealing. ${ }^{65}$ A closer inspection of the transformation of this planar organic molecule has revealed that it undergoes thermal dehydrogenation generating deh-DPDI $\left(-\mathrm{H}_{2}\right)$ and, potentially, subsequent ring closure and further dehydrogenation to the poly-azocyclic compound 3deh-DPDI $\left(-3 \mathrm{H}_{2}\right)$ (Figure 1).

Whereas deh-DPDI may act as a chelating endo-ligand on a metal surface, coordinating single metal atoms or forming 1D chain structures, the diazo units at both ends in 3deh-DPDI may bridge metal centers, rendering the latter a bridging exoligand capable of forming 2D-coordination networks. We will show that the observed reactivity and thus the degree of dehydrogenative conversion is specifically determined by the co-deposited or substrate-supplied transition metal adatoms. The geometry of the resulting coordination polymer depends also on the type (Au or $\mathrm{Cu}$ ) and crystal-index ((111), (100)) of the substrate.

In this report we focus on the assembly of on-surface coordination polymers by a two-stage reactive 
dehydrogenation of the amine and imine functional groups in DPDI. To investigate the impact of transition metal adatoms on the transformation of the building block and on the formed coordination architecture, we employ a broad portfolio of surface analytical techniques: Scanning Tunneling Microscopy (STM), X-Ray Photoelectron Spectroscopy (XPS), Near Edge X-ray Absorption Fine Structure (NEXAFS) measurements in combination with Density Functional Theory (DFT) computational modeling.

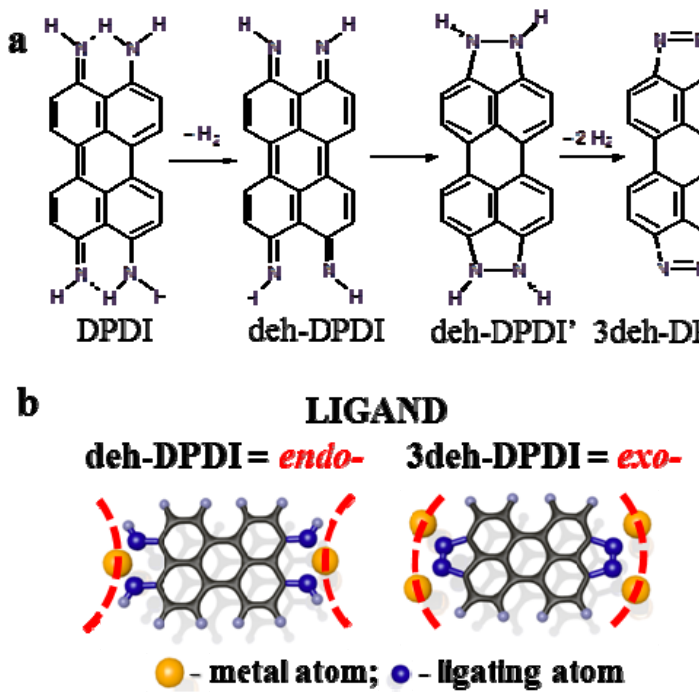

Figure 1. Dehydrogenation of DPDI to a quinoidal bisimino form deh-DPDI, which may act as an endo-ligand on a metal surface, and further cyclization and dehydrogenation resulting in triply dehydrogenated DPDI (3deh-DPDI) (Scheme a). In the latter, the diazo units may act as bridging ligands between metal centers, rendering 3deh-DPDI an exo-ligand capable of forming 2Dcoordination networks (b).

\section{EXPERIMENTAL SECTION}

All samples were prepared and investigated under Ultra-High Vacuum (UHV) conditions with a base pressure of $\sim 10^{-10}$ mbar. The crystal substrates were cleaned by cycles of sputtering with $\mathrm{Ar}^{+}$ions and subsequent annealing to $\sim 450^{\circ} \mathrm{C}$. The molecules were deposited on the surface by means of thermal evaporation at $\sim 240{ }^{\circ} \mathrm{C}$ from a commercial evaporator (Kentax $\mathrm{GmbH}$, Germany) and metal adatoms by e-beam evaporator, respectively. The amount of the sublimed compound was controlled by a quartz crystal microbalance.

STM images were obtained at $5 \mathrm{~K}, 77 \mathrm{~K}$ or at RT in a constant current mode (typical tunneling current 20-50 pA), the sample bias was selected in the range of $5 \mathrm{mV}-3 \mathrm{~V}$, such that the molecules appear in high contrast. Scanning probe tips were made from Pt-Ir wire (90\% Pt, 10\% Ir) and cleaned by sputtering with $\mathrm{Ar}^{+}$ions.

XPS was used to estimate the coverage of DPDI and to verify the stoichiometry after deposition. Also by XPS the element-specific chemical environment (analysis of $\mathrm{C} 1 \mathrm{~s}$ and N1s signatures), in particular the coordination of DPDI with different metal ligands, was tracked. A monochromatized Al-
$\mathrm{K}_{\alpha} \mathrm{X}$-ray source was used. The instrumental setup gives a full width at half maximum (FWHM) of $1.0 \mathrm{eV}$. The energy calibration was performed using a $\mathrm{Au}(111)$ reference. All XPS data were obtained at room temperature and the spectra were recorded in normal emission unless stated otherwise.

The NEXAFS measurements were performed on samples held at room temperature at the Surface/Interface: Microscopy (SIM) beam-line of the Swiss Light Source (SLS) using total electron yield acquisition mode. ${ }^{66}$ The spectra were divided by the background obtained on the clean substrate and normalized to pre-edge. The fitting analysis of the spectra was performed by asymmetric Gaussian functions with linearly increasing FWHM for higher photon energies ${ }^{67}$. The onset of the ionization potential was fitted by a broadened step-function.

Periodic DFT modeling was performed with the VASP $\operatorname{code}^{68}$ using the projector-augmented wave method ${ }^{69}$ for describing ion-core interactions. Van der Waals interactions were included using the van der Waals density functional, ${ }^{70}$ while local correlation was described by Local-Density Approximations (LDA). The semi-local exchange was described in the Generalized Gradient Approximation (GGA) using an optimized form of the Becke 86 functional. ${ }^{71}$

The $\mathrm{Cu}(111)$ surface was modeled by a four-layered slab separated by $15 \AA$ of vacuum, with a $\mathrm{p}(10 \times 10)$ surface unit cell for the 3deh-DPDI honeycomb network, as previously determined. ${ }^{65}$ For the deh-DPDI chains we used the unit cell illustrated in Figure S7, which gave the most stable structure (see SI for calculations with other unit cells). The calculated lattice constant, obtained with the methods described here, of $3.598 \AA$ was used. In all calculations the plane waves were expanded to a kinetic energy cutoff of $500 \mathrm{eV}$. For the honeycomb network the $1^{\text {st }}$ Brillouin zone was sampled by the $\Gamma$-point only, while for the Co-coordinated deh-DPDI chains a $3 \times 2 k$-point sampling was used. All structures were structurally optimized until the residual forces of all atoms, except for the bottom two layers of the slab, kept fixed, were smaller than $0.01 \mathrm{eV} / \AA$.

Simulated core-level shifts were obtained by comparing total energy differences between core-ionized and ground state systems. The total energies of core-ionized systems were computed by using a core-ionized PAW potential for the coreionized atom as described by Köhler and Kresse ${ }^{72}$.

\section{RESULTS AND DISCUSSION}

Dehydrogenation of DPDI and endo-/exo-ligand formation, controlled by the type of adatoms present on the surface.

First, we investigated the dehydrogenation of adsorbed DPDI on $\mathrm{Cu}$ surfaces. The changes in the chemical environment of $\mathrm{N}$ upon reaction of DPDI with adatoms were monitored by XPS (N1s peak) and are represented in Figure 2. Unreacted DPDI, after deposition on $\mathrm{Cu}(111)$ and $\mathrm{Cu}(100)$ substrates, gives rise to two peaks in the N1s spectrum corresponding to the coexisting amino- $(\sim 399.4 \mathrm{eV})$ and imino-group $(\sim 397.5 \mathrm{eV})$ (Figure 2a; cf. Figure S1 in Supporting Information (SI)). The observed XPS peak positions correspond well to the values reported in the literature (see XPS values in Table S1, S2 of the SI). ${ }^{73,74}$ In spite of the 1:1 stochiometry between amino and imino nitrogen, we observe unequal intensities of the amine- 
and imine-peak even in the native multilayer (cf. Fig S3). We tentatively attribute this to intramolecular hydrogen-bonding ($\mathrm{NH}_{2} \ldots \mathrm{N}=$, cf. Fig. 1a) which has been found to yield significant peak shifts ${ }^{75,76}$ and potentially photoelectron scattering effects. ${ }^{77}$ The position of the observed N1s peaks of the DPDI monolayer on $\mathrm{Cu}(111)$ corresponds well to the XPS data of the DPDI multilayer, indicating that neither dehydrogenation nor $\mathrm{Cu}$ coordination does occur at room temperature (Figure $\mathrm{S} 3$ ). Even after deposition of $\mathrm{Cu}$ adatoms onto the monolayer of DPDI on $\mathrm{Cu}(111)$, there is no significant modification of the chemical environment of $\mathrm{N}$ as monitored by the N1s peaks (cf. Figure S4 in SI). Thus, DPDI remains unreacted irrespective of whether it is adsorbed on $\mathrm{Cu}$ at room temperature or whether higher thermal energy adatoms from a sublimation source are provided.

Annealing to $300{ }^{\circ} \mathrm{C}$ promotes a chemical transformation of DPDI on the $\mathrm{Cu}(111)$ and $\mathrm{Cu}(100)$ substrates, and leads to characteristic changes in the N1s XPS signature. The modified spectrum is characterized by a single N1s peak at $\sim 399.4 \mathrm{eV}$ reflecting an identical chemical environment of the $\mathrm{N}$ atoms contained in 3deh-DPDI (Figure 2c, Figure S1). The N1s binding energy of $\mathrm{Cu}$-coordinated 3deh-DPDI corresponds well to the energies reported for related azo-functionalized species. ${ }^{78}$ Moreover, we calculated the average N1s core level shift between imine $\mathrm{N}$ contained in isolated DPDI on the surface and the azo-N contained in Cu-coordinated 3dehDPDI. The resulting shift of $+1.56 \mathrm{eV}$ is within the experimental error margin. This reaction is exothermic with a reaction energy of $-0.55 \mathrm{eV}$ per molecule. The transformation of DPDI into 3deh-DPDI, containing azo $\mathrm{N}$ at both ends, is also supported by the NEXAFS data (vide infra).

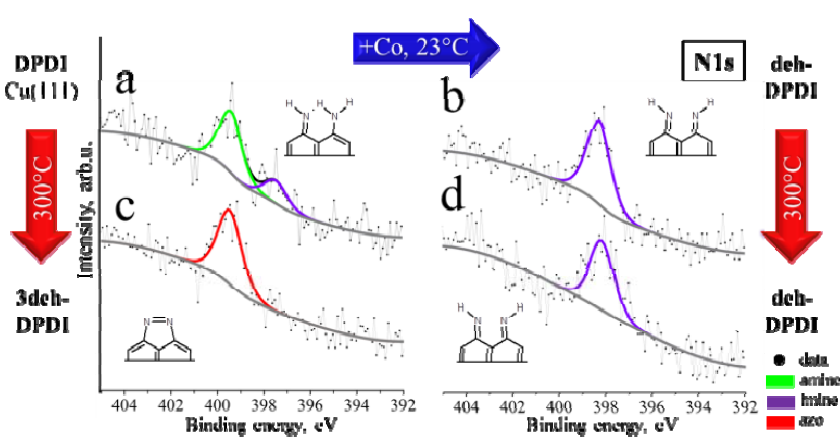
$E_{\text {roust }}=-0.55 \mathrm{eV} /$ molecule

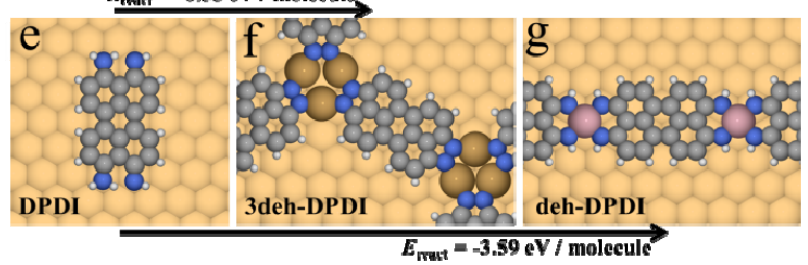

Figure 2. Identification of the various $\mathrm{N}$ species in the N1s XP spectra of DPDI on $\mathrm{Cu}(111)$ : (a) Native DPDI is characterized by two peaks corresponding to amino- (green) and imino- (violet) groups. (b) Upon addition of Co adatoms to native DPDI on $\mathrm{Cu}(111)$ at $\mathrm{RT}$, the dehydrogenation occurs readily as recognized by the dominant NH- peak (violet). (c) Annealing of native DPDI on $\mathrm{Cu}(111)$ to $300{ }^{\circ} \mathrm{C}$ leads to a different reaction product: One peak is visible in the N1s XPS data at the higher binding energy
(BE), which is attributed to azo nitrogen $(\mathrm{N}=\mathrm{N})$. (d) Annealing of the DPDI / $\mathrm{Cu}(111)$ in the presence of Co adatoms to $300{ }^{\circ} \mathrm{C}$ does not modify a deh-DPDI product. Chemical schemes: Note that the arrangement of the free electron pairs of the $=\mathrm{NH}$ (imine) and $\mathrm{N}=\mathrm{N}$ (azo) ligands determines the role of deh-DPDI as an endo ligand and of 3deh-DPDI as an exo-ligand, respectively. The DFT models with calculated reaction energies (e) the isolated DPDI, (f) the $\mathrm{Cu}$-coordinated 3deh-DPDI and $(\mathrm{g})$ the Co-coordinated dehDPDI cases. The average N1s core-level shifts with respect to the imine-N atoms of native DPDI are: $+1.56 \mathrm{eV}$ for $3 \mathrm{deh}-\mathrm{DPDI}$, $+0.69 \mathrm{eV}$ for deh-DPDI.

Notably, deposition of $\mathrm{Cu}$ adatoms onto DPDI on the more inert $\mathrm{Au}(111)$ substrate, triggers the same chemical reaction leading to 3deh-DPDI-Cu complexes, upon annealing to $\sim 300^{\circ} \mathrm{C}$ (however, the reaction proceeds only for a part of the compound, cf. S5 and discussion in the SI).

The reaction products after annealing DPDI at $300^{\circ} \mathrm{C}$ on both $\mathrm{Cu}(111)$ and $\mathrm{Cu}(100)$ substrates were visualized by room temperature STM. These experiments reveal the formation of a highly ordered 2D hexagonal porous network on $\mathrm{Cu}(111)^{65}$ and a moderately ordered $2 \mathrm{D}$ rectangular network on $\mathrm{Cu}(100)$, respectively (Figure 3). The XPS data confirm that both networks consist of 3deh-DPDI in the role of an exo-ligand (cf. Fig. 2 and SI). The symmetry of the surface is directly reflected by the symmetry of the network (Figure 3a,b,e and $3 \mathrm{c}$, d,f respectively). Due to the reduced commensurability of the rectangular coordination network with the $\mathrm{Cu}(100)$ surface lattice and the co-existence of square and rectangular pores (Figure $3 \mathrm{~h}, \mathrm{i}$ ), the amount of defects is greater and long-range order is accordingly reduced compared to the corresponding structure on $\mathrm{Cu}(111)$.

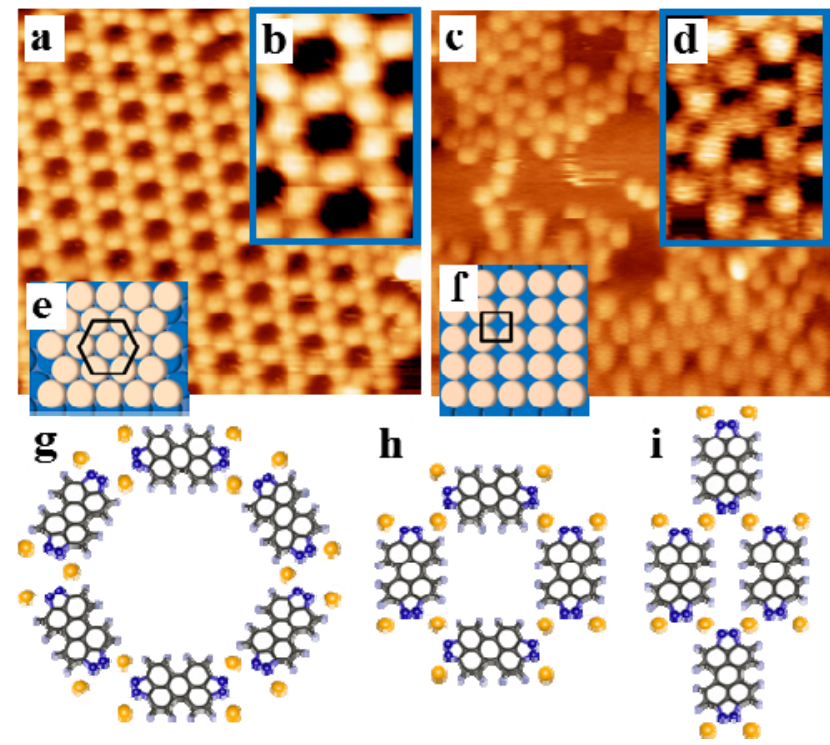

Figure 3. Annealing native DPDI at $300{ }^{\circ} \mathrm{C}$ on $\mathrm{Cu}$ substrates leads to the formation of exo-ligating $3 \mathrm{deh}-\mathrm{DPDI}$. The resulting $\mathrm{Cu}$-coordinated 2D-polymer reflects the symmetry of the underlying substrate: $(a, b)$ hexagonal pores are formed on the $\mathrm{Cu}(111)$ surface and $(\mathrm{d}, \mathrm{e})$ rectangular pores on the $\mathrm{Cu}(100)$ surface, as depicted in the STM images $\left(19 \times 19 \mathrm{~nm}^{2}\right.$ and $\left.4 \times 6 \mathrm{~nm}^{2}\right)$. The hexagonal and rectangular symmetry for $\mathrm{Cu}(111)$ and 
$\mathrm{Cu}(100)$ surfaces are depicted in the insets (e) and (f), respectively. Schematic models: (g) hexagonal 3deh-DPDI pore; $(h, i)$ rectangular pores in two configurations: with parallel or perpendicular orientation and corresponding rectangular or square symmetry of the coordination polymer, respectively.

The role of the open d-shell metals, like $\mathrm{Co}, \mathrm{Fe}$ and $\mathrm{Ni}$, in the on-surface reaction of DPDI on $\mathrm{Cu}(111)$, was studied in a dedicated series of experiments: After deposition of DPDI and subsequent deposition of cobalt atoms at room temperature, the N1s XPS spectrum, presented in Figure 2b, shows significant changes from native DPDI. The amino-peak, which is characteristic for the unreacted compound, disappears (Fig. 2b) and only single N1s peak is observed at $\sim 398.3 \mathrm{eV}$. The energy position differs significantly (1.1 eV lower), from the one observed after $\mathrm{Cu}$ coordination of 3deh-DPDI on $\mathrm{Cu}(111)$, and is assigned to imino-nitrogen atoms. ${ }^{79,80}$ Upon annealing at $\sim 300{ }^{\circ} \mathrm{C}$ the $\mathrm{N} 1 \mathrm{~s}$ peak remains virtually unchanged $(\sim 398.1 \mathrm{eV})$ (Figure $2 \mathrm{~d})$. The core level shift between this Co-coordinated imine and the uncoordinated imine $\mathrm{N}$ has been calculated to be $0.69 \mathrm{eV}$, which compares well to the experimental data. (Fig. 2e, g). Based on DFT modeling, the calculated reaction energy is $-3.59 \mathrm{eV}$ for transforming DPDI into Co-coordinated deh-DPDI.

The same type of transformation occurs for DPDI on a $\mathrm{Au}(111)$ substrate (Figure 4a) in the presence of Co adatoms (Figure 4c,f). Moreover, other open 3d-shell transition metal adatoms, such as $\mathrm{Fe}$ and $\mathrm{Ni}$, initiate an identical transformation of DPDI on $\mathrm{Au}(111)$ as recognized in the XPS data showing the dominant imino-peak at low binding energy $\sim 398 \mathrm{eV}$ (Ni: Figure 4d and Fe: Figure b,e).

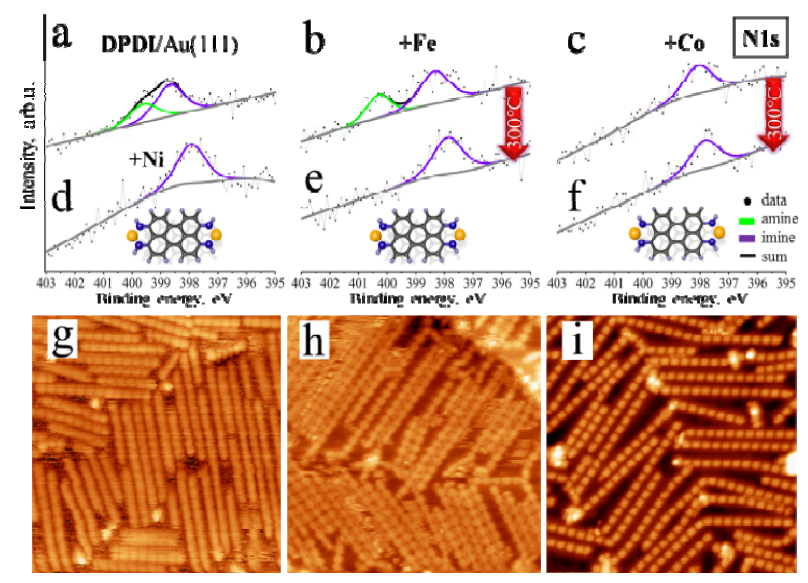

Figure 4. Transformation of DPDI into deh-DPDI (an endoligand) in the presence of $\mathrm{Ni}, \mathrm{Fe}$ and $\mathrm{Co}$ on $\mathrm{Au}(111)$. This transformation occurs at RT in an on-surface reaction between DPDI and transition metal adatoms as recognized by the change of (a) initial two peaks in N1s spectrum of DPDI on Au(111) into (b)-(f) dominant N1s XPS peak of imine-character. (b) The shoulder of the amine corresponds to small amounts of the unreacted DPDI, which disappear after annealing. The resulting chelating ligand coordinates with adatoms and arranges into a chain architecture. (g-i) STM micrographs of the polymers, created by co-deposition of DPDI with (g) Ni, (h) Fe and (i) $\mathrm{Co}$ adatoms on $\mathrm{Au}(111)$ at $\mathrm{RT}\left((\mathrm{g}) 30 \times 30 \mathrm{~nm}^{2}\right.$ at RT; (h),(i) $30 \times 30$ $\mathrm{nm}^{2}$ at $5 \mathrm{~K}$ ). Note, the polymers observed in STM are not modified upon annealing.

Annealing of the samples to $300^{\circ} \mathrm{C}$ only completes a conversion of the unreacted compound (e.g. Figure 4e), however, does not change the final reaction product. The dominant XPS signature is assigned to deh-DPDI (see Fig. 1), which is reminiscent of the ubiquitous acac (acetylacetonato) ligands in coordination chemistry. This ligand is able to act as a ditopic chelating endo-ligand for the co-deposited transition metals. Therefore, the formation of metal complexes, with two of these bis(imine) units in a square-planar coordination geometry on the different substrates, gives rise to $1 \mathrm{D}$ coordination polymers as depicted by STM in Figure 4g-i.

The analysis of the XPS data reveals two types of reaction products for closed vs. open d-shell adatoms coordinating with DPDI. $\mathrm{Cu}$ adatoms transform DPDI into 3deh-DPDI that may act as a bridging exo-ligand with its convex arrangement of donor atoms. On the other hand, in the presence of $\mathrm{Co}, \mathrm{Fe}, \mathrm{Ni}$ adatoms the less dehydrogenated species deh-DPDI, that acts as a ditopic bis(chelating) endo-ligand, are trapped by coordination to the heterometal atoms, forming the chain-like 1D coordination polymers. The adatom-dependent transformations of DPDI to deh-DPDI or 3deh-DPDI and coordination to the respective transition metals represent complex multistep processes. Only detailed computational modeling of all possible reaction pathways/sequences on the metal surface(s) would provide insight into the factors governing the final product(s) observed in the transformations described above.

NEXAFS study of the surface-transformed DPDI: Identification of amino-, imino- and azo-nitrogen.

To confirm the assignment of the deh-DPDI and 3deh- DPDI dehydrogenation product in the on-surface coordination polymers, we have employed NEXAFS. The method provides a characteristically different probing mechanism from XPS in that transitions from occupied N1s to unoccupied N2p orbitals are examined. The method is sensitive to both the chemical environment and the orientation of the molecule. Figure 5 displays the NEXAFS data obtained for three samples, (a) unreacted DPDI/Cu(100) (not annealed), (b) DPDI + $\mathrm{Co} / \mathrm{Cu}(111)$ and (c) DPDI/Cu(111) (annealed to liberate $\mathrm{Cu}-$ adatoms and to activate the on-surface reaction). The data is summarized in Table 1, along with the corresponding assignments of the peaks.

The relative orientation of the unoccupied states with respect to the incident X-ray beam as determined in angledependent NEXAFS experiments modifies the magnitude of the spectral features. In the present case, electronic states with their nodal plane in out-of-plane orientation were probed in grazing incidence $\left(70^{\circ}\right.$ off the surface-normal) with the linear polarization perpendicular to the surface-plane (blue curves in Figure 5). In comparison, the signature of electronic states with their nodal plane oriented in-plane were probed in normal incidence with the polarization of the incident X-ray light oriented parallel to the surface-plane (red curves in Figure 5). The signature of the transitions states derived from $\mathrm{C}-\mathrm{N}$ and $\mathrm{N}-\mathrm{N}$ bonds (vida infra) clearly establishes that the molecules are oriented in the surface plane. 
Table 1. Energies of the NEXAFS N1s peaks, obtained from the fit of data, correspond to amino, imino and azo groups.

\begin{tabular}{l|llll}
\hline (b) deh-DPDI & 398.7 & - & 409.8 & - \\
\hline (c) 3deh-DPDI & 399.6 & 401.2 & 407.0 & 410.7 \\
\hline
\end{tabular}

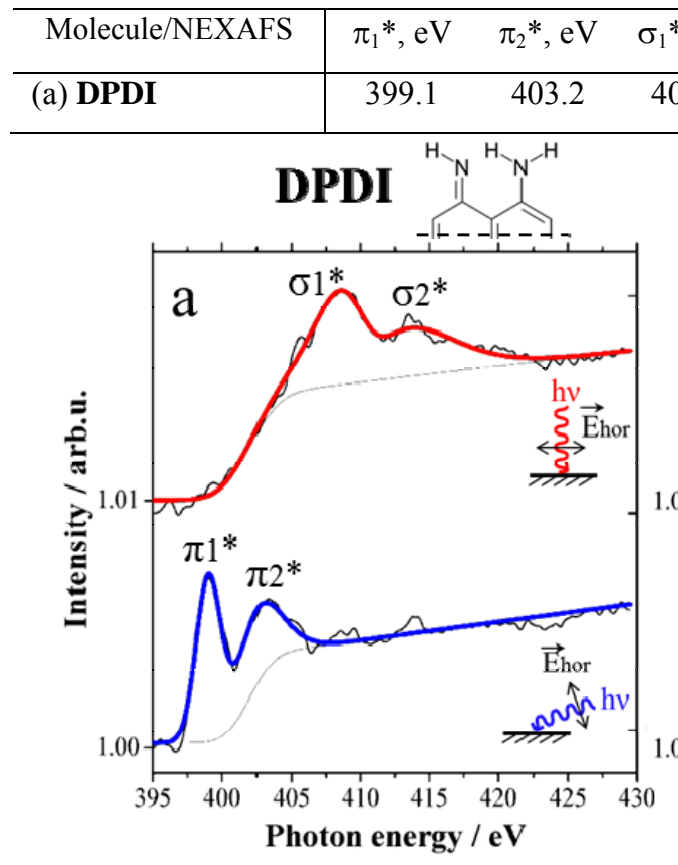

\begin{tabular}{cc}
$\sigma_{1}^{*}, \mathrm{eV}$ & $\sigma_{2}{ }^{*}, \mathrm{eV}$ \\
\hline 408.6 & 414.4
\end{tabular}
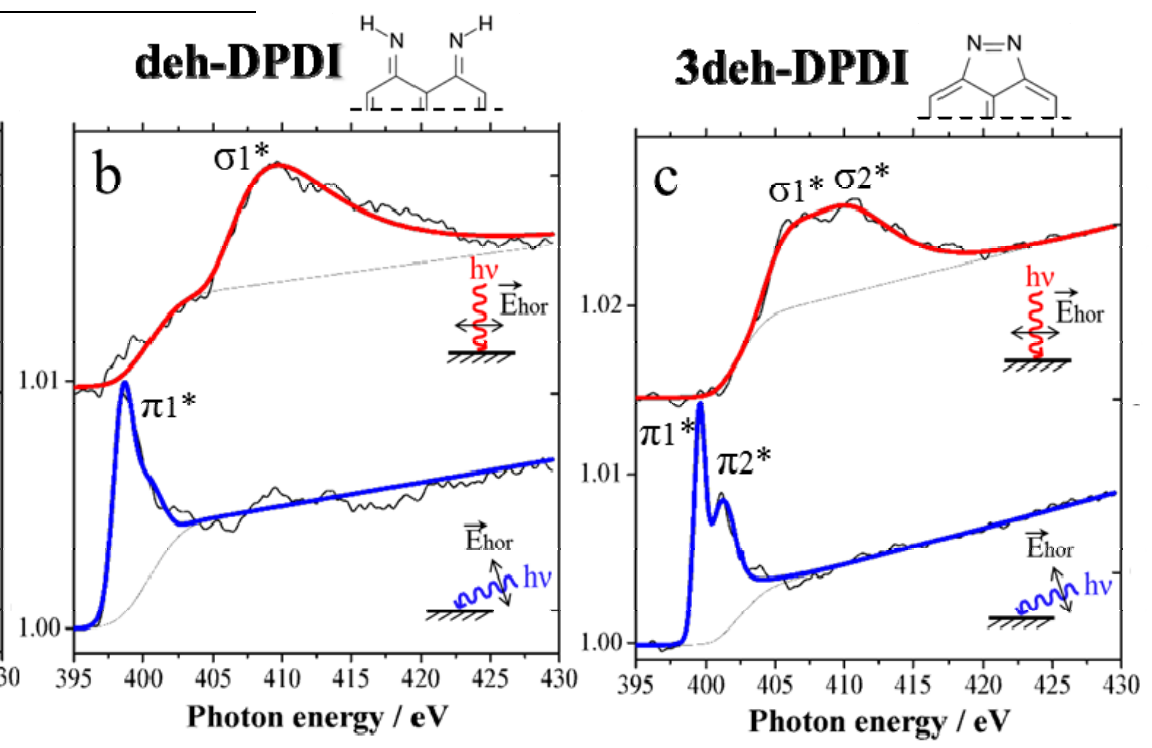

Figure 5. NEXAFS data revealing different DPDI species. In-plane $\sigma^{*}$ and $\pi^{*}$ resonances are reflected by red and blue curves, respectively. (a) Spectra of unreacted DPDI on $\mathrm{Cu}(100)$ contains both amino- and imino- peaks; (b) spectra of deh-DPDI coordinated to Co via imino-nitrogen; (c) spectra of 3deh-DPDI coordinated to $\mathrm{Cu}$ via azo-nitrogen.

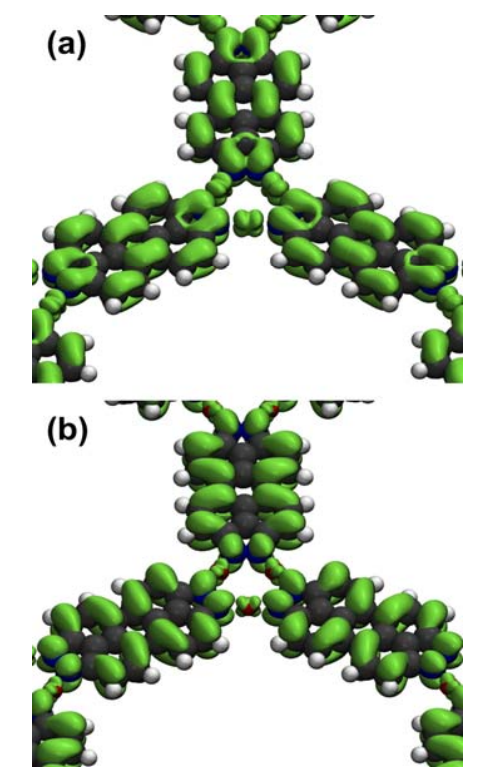

Figure 6. Numerical simulation of $\mathrm{Cu}$ coordinated 3deh-DPDI: Absolute contour plots of the (a) HOMO and (b) LUMO of the freestanding 3deh-DPDI network, represented by the banddecomposed density of states closest to the Fermi level below and above the Fermi level, respectively. The value of the contours is $0.005 e / \AA^{3}$.

For the identification of the different $\mathrm{N}$ species, we analyze the nitrogen K-edge NEXAFS signature of native DPDI on $\mathrm{Cu}(100)$ as presented in Figure 5a. We observe two N species via their $\pi^{*}$ states $(403.2 \mathrm{eV}$ and $399.1 \mathrm{eV})$ as well as by their $\sigma^{*}$ states (414.4 eV and $408.6 \mathrm{eV}$ ). The transition energies correspond well with the literature values reported for $\mathrm{N}$ atoms of amine and imine character ${ }^{81,82}$ (Supporting Info: Table S3). Note that XPS of unreacted DPDI deposited on $\mathrm{Cu}(100)$ samples also revealed two different N1s signals, corresponding to the amine and imine nitrogen atoms (Supporting Info: Figure S1a). In case of co-deposited DPDI and $\mathrm{Co}$ on $\mathrm{Cu}(111)$, the observed $\mathrm{N}$ K-edge NEXAFS signal differs significantly (Figure 5b).

The spectrum corresponding to DPDI with Co adatoms revealed only a single $\pi^{*}$ peak $(398.7 \mathrm{eV})$ and a single $\sigma^{*}$ peak (409.6 eV), which is consistent with only one type of (imine) nitrogen ${ }^{80}$. This confirms the structural assignment provided above on the basis of the XPS data: The 1D coordination polymer is assigned to Co-deh-DPDI. The 2D coordination polymer formed by $\mathbf{D P D I} / \mathrm{Cu}(111)$ after annealing has been assigned to a porous 3deh-DPDI-Cu network. In this case, the $\mathrm{N}$ K-edge NEXAFS signature reveals again very different features compared to the previous cases. Split peaks corresponding to the transitions between the $\pi^{*}(401.2 \mathrm{eV}$ and $399.6 \mathrm{eV}$ ) and $\sigma^{*}$ states $(410.7 \mathrm{eV}$ and $407.0 \mathrm{eV}$ ) (Figure 5c) 
are observed. Their energies correspond well to the proposed azo-bridges ${ }^{78,83-85}$ formed upon threefold dehydrogenation of the DPDI molecules, as identified already on the basis of XPS. The assignment of unreacted DPDI and of deh-DPDI in the NEXAFS data is unambiguous. The NEXAFS signals attributed to the azo-N atoms in 3deh-DPDI, in contrast, requires additional analysis. The observation of the split $\pi^{*} \mathrm{~N}$ peak in case of copper-coordinated 3deh-DPDI on $\mathrm{Cu}(111)$ is unexpected on the grounds of the $\mathrm{N}$ species alone. We relate this to 'donation/back-donation' effects coming from the coordination of 3deh-DPDI with the copper atoms. ${ }^{78}$ Specifically, the occupied/unoccupied metal centered orbitals mix with the lowest unoccupied molecular orbital (LUMO) / highest occupied molecular orbital (HOMO) of the molecule, respectively. In the case at hand, this would primarily involve the azo-bridge of 3deh-DPDI and the $\mathrm{Cu}$ adatoms. In order to support the proposed donation/back-donation model as a reason for the split $\pi^{*} \mathrm{~N}$ peak, a DFT modeling study was carried out.

The extended degeneracy of the molecular orbitals across the $\mathrm{Cu}$ coordinated 3deh-DPDI on $\mathrm{Cu}(111)$ can be recognized in the numerical simulations as well. In Figure 6 the electron density of the frontier orbitals of the freestanding 3deh-DPDI network is illustrated which reflects the bonding in the network: the $p_{z}$ states of the molecule mix with the $d$ states of the $\mathrm{Cu}$ atoms. Notably, both the HOMO and the LUMO consist of three electronic states (one per molecule in the unit cell) with their degeneracy lifted due to the molecule-adatom interactions as represented in Figure 7a-b.

The partial density of states (PDOS) of the molecule's $\mathrm{N}$ atoms is significantly altered due to the interaction with the coordinating $\mathrm{Cu}$-adatoms. The calculations of the 3deh-DPDI reveal a splitting of the peaks in the $p_{z}$ component of the PDOS localized on the $\mathrm{N}$ atoms in vacuum (Figure 7a) after $\mathrm{Cu}$ coordination (Figure 7b). This splitting pertains when including the $\mathrm{Cu}(111)$ surface in the simulations (Figure 7c). Notably, Co-coordinated deh-DPDI chains on $\mathrm{Cu}(111)$ give rise to a single (not split) peak in the $p_{z}$ component of the PDOS of nitrogen (see Fig. S9 of SI).

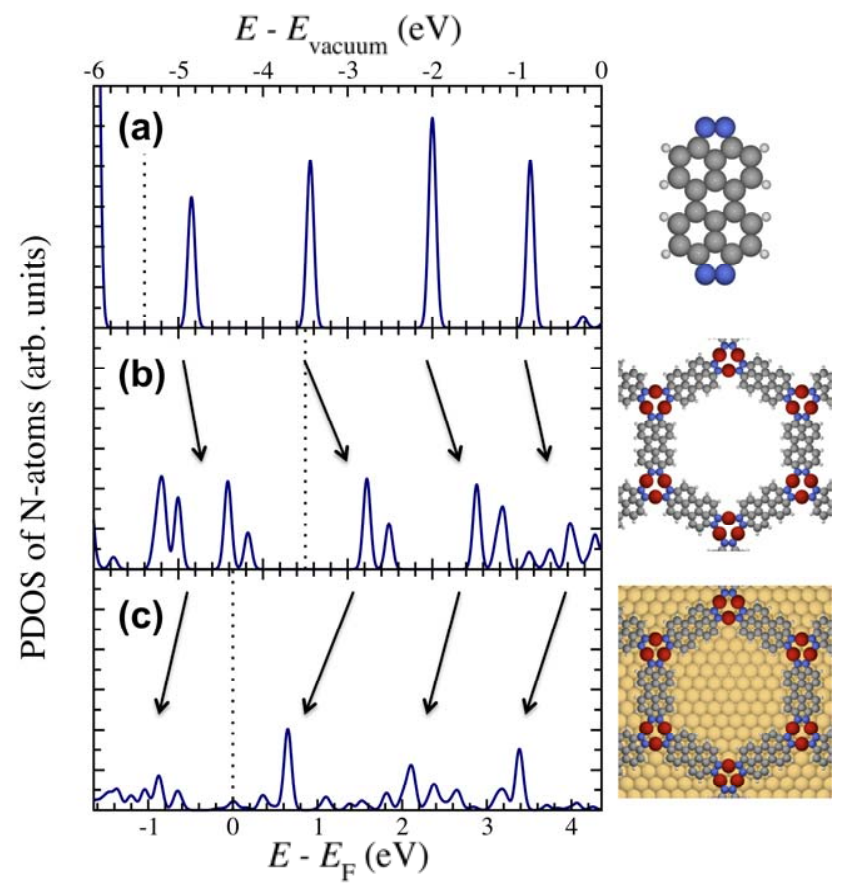

Figure 7. The $\pi$-donation/back donation effect upon $\mathrm{Cu}$ coordination of $3 d$ eh-DPDI causes a split in the $\pi^{*}$ state, which appears as a double peak in the N K-edge NEXAFS. The partial density of states (PDOS) (a) of the $p_{\mathrm{z}}$ component on the $\mathrm{N}$ atoms of the 3deh-DPDI becomes modified by coordination to $\mathrm{Cu}$ adatoms, both for the (b) freestanding and (c) the surfacesupported coordination polymer.

Endo-/exo- DPDI coordination defines the dimensionality of the on-surface polymer

In the case at hand, the surface deposited DPDI molecule acts as a ligand precursor, which is transformed to a ligating structural building block by adatom-specific dehydrogenation $\left(-1 \mathrm{H}_{2}\right.$ or $\left.-3 \mathrm{H}_{2}\right)$. Please note, the hydrogen may be lost as atomic (presumably forming metal-hydrides) or as molecular hydrogen $\left(\mathrm{H}_{2}\right.$ gas). The control of polymer topology via endo/exo ligation provides an example of site-specific chemistry in an oligomerization reaction (Figure 8). The linear polymeric structures formed by deh-DPDI are imposed by the ditopic nature of the chelating endo-ligand, which connects metal centers via the two inward pointing free electron pairs belonging to the $\mathrm{N}$ atoms at either end of the DPDI molecule (Figure 8, left). The 3deh-DPDI, which is generated in the presence of $\mathrm{Cu}$ adatoms, exhibits a characteristically different arrangement of the free $\mathrm{N}$ electron pairs while acting as exoligand in the coordination. The construction of the network node also depends on the symmetry of the substrate: On $\mathrm{Cu}(111)$ three adatoms connect three 3deh-DPDI molecules in the form of a hexagonal network (Figure $8 \mathrm{f}$ and Figure 3a,b,g). On $\mathrm{Cu}(100)$ four adatoms interconnect four 3deh-DPDI molecules in each node thereby forming a tetragonal network (Figure $8 \mathrm{~d}$ and Figure 3c,d,h,i). At low coverage of 3dehDPDI on $\mathrm{Cu}(100)$ substrates, however, oligomers nucleate in a bridge-to-bridge fashion, initiating a 1D arrangement (Figure 8 e and Figure S2 in SI). The N1s peak in the XPS data is not 
modified with increasing sub-monolayer coverage indicating that the chemical environment of the nitrogen atoms remains the same irrespective of whether a $1 \mathrm{D}$ or a $2 \mathrm{D}$ coordination polymer is present. This supports the notion that the 3dehDPDI ligands are fully $\mathrm{Cu}$-decorated at all coverages. We note that initiating the reaction with $\mathrm{Cu}$ adatoms requires the highest temperature $\left(300{ }^{\circ} \mathrm{C}\right)$. This is consistent with the position of $\mathrm{Cu}$ on the scale of the second ionization energies of the different atoms studied here. The oxidation state of the coordinating atom in the 'on-surface' configuration is not trivial to define, as the intermixing between the electronic states of the reacted molecules and the surface has to be taken into account. ${ }^{86,87}$
The interconnection of the exo-coordinated ligands via $\mathrm{Cu}$ adatoms depends critically on the chemical nature of the substrate. In spite of the $\mathrm{Cu}$ coordination of 3deh-DPDI, as seen by XPS, no RT-stable arrangements were observed on $\mathrm{Au}(111)$ by STM. However, after cooling the sample to $5 \mathrm{~K}$, single coordinated molecules as well as their vdW condensed islands (Fig. 8g, Fig. S3c-e) have been visualized. The fact that 3deh-DPDI molecules do not form a coordination polymer on this substrate may be related to one or more of the following factors: (1) a mismatch between the surface registry and the length of the coordination bond (2) an interaction between an electronic state of the substrate and the coordinated ligand or (3) the modified interaction between $\mathrm{Cu}$ adatoms and the $\mathrm{Au}$ substrate in comparison to the $\mathrm{Cu}$ substrate.

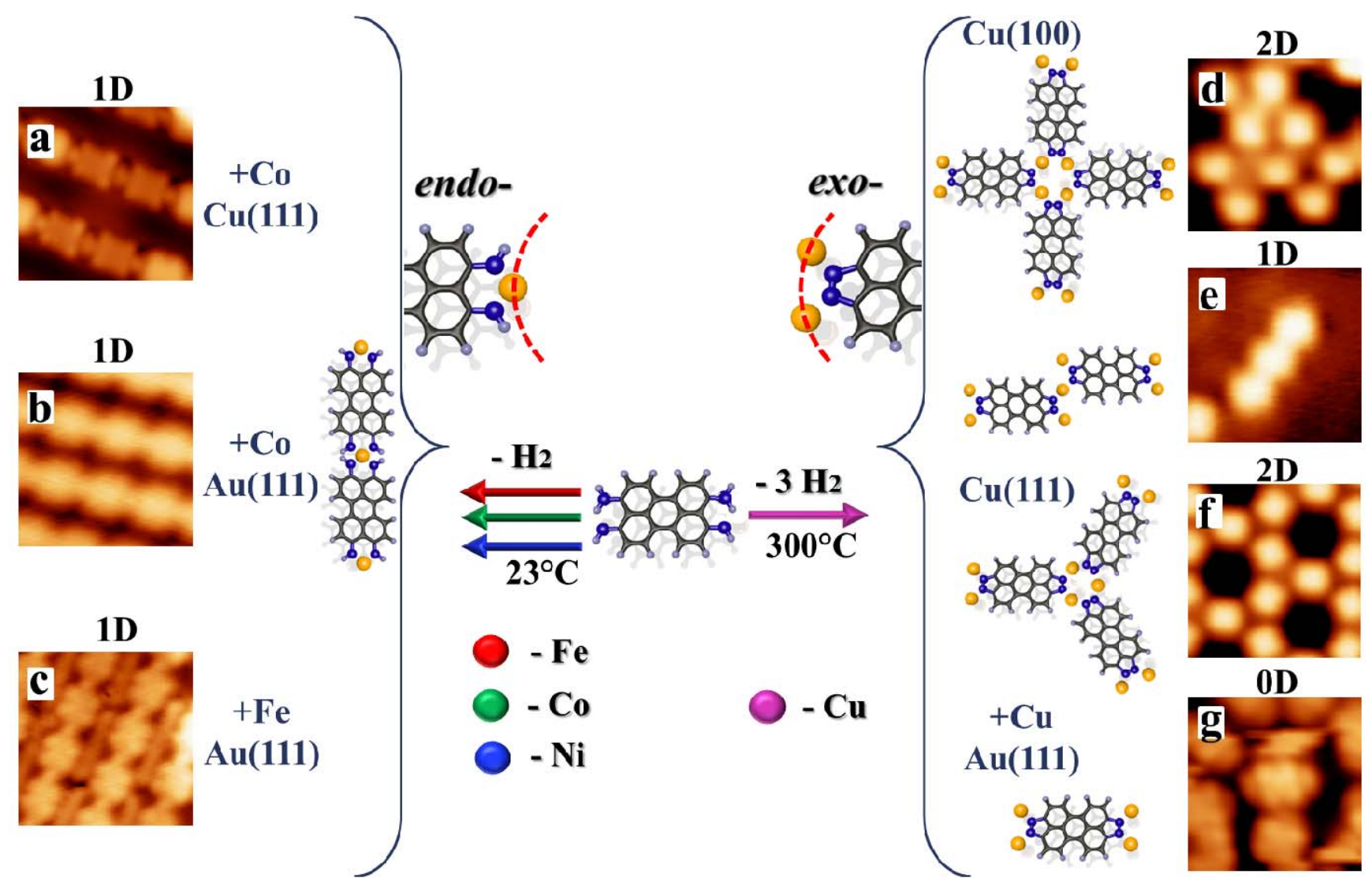

Figure 8. Depending on their reaction partner dehydrogenated DPDI molecules can act as either endo- or exo-ligands in the formation of on-surface coordination polymers. (Top center) The two possible polymerization reactions depend on the involved adatoms (Fe, Co, Ni, $\mathrm{Cu}$ ) as indicated by the schematic representation and the arrows. Colors indicate the chemical species of adatoms as depicted in the legend; (left) deh-DPDI, an endo-ligand, forms a 1D coordination polymers, while 3deh-DPDI (right), an exo-ligand, forms a 2Dcoordination polymers. STM images ((a)-(d), (f), (g) $4 \times 4 \mathrm{~nm}^{2}$, (e) $5 \times 5 \mathrm{~nm}^{2}$ taken at $5 \mathrm{~K}$ ) reveal the chain vs. network character of the formed polymers. (a) - (c) Co or Fe adatoms transform DPDI into deh-DPDI already at RT. In all these cases, the endo-type ligation leads to the formation of straight chains on $\mathrm{Cu}(111)$ and $\mathrm{Au}(111)$. (d) Annealing of DPDI on $\mathrm{Cu}(100)$ promotes a formation of an exo-ligated poly-Cu-3deh-DPDI network with rectangular symmetry. (e) At low coverage the bridge-to-bridge 1D arrangement are observed. (f) Annealing of DPDI on $\mathrm{Cu}(111)$ promotes a formation of an exo-ligated poly-Cu-3deh-DPDI network with hexagonal symmetry. (g) Sublimation of DPDI and $\mathrm{Cu}$ adatoms on $\mathrm{Au}(111)$ and subsequent annealing to $300{ }^{\circ} \mathrm{C}$ promotes the formation of isolated, but fully $\mathrm{Cu}$ coordinated 3deh-DPDI. The tunneling parameters for the STM-imaging were optimized for visualization of the coordinating metal adatoms, which appear as protrusions. Notably for poly-Cu-3deh-DPDI no adatoms have been visualized by STM. $^{36}$ 


\section{CONCLUSIONS}

The on-surface reactivity of DPDI molecules, and thus the degree of dehydrogenative conversion into either an endo- or exo-ligand depends neither on the nature $(\mathrm{Au}$ or $\mathrm{Cu})$ nor on the crystal-index $(111,100)$ of the substrate, but is exclusively determined by the metal adatoms. In the presence of $\mathrm{Fe}$, Co and $\mathrm{Ni}$ adatoms the reaction proceeds to deh-DPDI as a ditopic chelating endo-ligand. This ligand is "trapped" by coordination with the metal adatoms in the formation of 1D coordination polymers. Only in presence of $\mathrm{Cu}$ adatoms and at elevated temperatures, the dehydrogenation proceeds to 3dehDPDI containing two $\mathrm{N}_{2}$ azo units. Here the two ligating $\mathrm{N}$ atoms are linked to two $\mathrm{Cu}$ atoms in a convex arrangement at either end of the 3deh-DPDI. Therefore, two types of molecular building blocks are generated, which differ in the encoded structural information: Due to the characteristic difference in the orientation of the ligating functional groups, the endo-ligand deh-DPDI forms 1D coordination polymers, whilst the exo-ligating 3deh-DPDI acts as bridging building block in 2D surface networks. In the latter case, the resulting architecture also depends critically on the chosen substrate: While the reaction itself progresses in the same way, irrespective of whether $\mathrm{Cu}$ adatoms are available on $\mathrm{Cu}(111)$, $\mathrm{Cu}(100)$ and $\mathrm{Au}(111)$, the porous network is observed only on the $\mathrm{Cu}$ substrates.

In conclusion, DPDI provides an instructive example of on-surface reactivity which crucially depends on the adatom chemistry. The combined interplay of all critical factors leads to a remarkable structural variety and the possibility to control the dimensionality and architecture of the surface aggregates. Future research will focus inter alia on the reaction mechanisms leading to such new architectures, including detailed theoretical modeling of the reaction sequences involved, and on the exploration the structure-property relationships. This is geared towards designing novel surface materials with tunable, characteristic properties occurring from the interaction of the coordination polymers with the surface.

\section{ASSOCIATED CONTENT}

Supporting Information. The following content supplied as Supporting Information: Additional XPS and STM data, Tables of XPS values and references; NEXAFS Table of references; DFT models; PDOS graphs. This material is available free of charge via the Internet at http://pubs.acs.org.

\section{AUTHOR INFORMATION}

Corresponding Authors

aneliia.shchyrba@unibas.ch; thomas.jung@psi.ch;

lutz.gade@uni-hd.de

Present Address

${ }^{\&}$ Institute of Condensed Matter Physics (ICMP), Ecole Polytechnique Fédérale de Lausanne (EPFL), Station 3, CH1015, Switzerland

\section{ACKNOWLEDGMENT}

We gratefully acknowledge the financial support from the National Centre of Competence in Research "Nanoscience" (NCCR-Nano), Swiss Nanoscience Institute (SNI), Swiss National Science Foundation (grants No. 200020-137917, 206021-113149, 206021-121461) and the São Paulo Research Foundation (grant \#2013/04855-0). We also thank the University of Heidelberg for funding. The XPS measurements were performed at the Laboratory for Micro- and Nanotechnology at the Paul Scherrer Institute (PSI). The authors sincerely thank R. Schelldorfer and M. Martina for the technical support during measurements, as well as $\mathrm{H}$. Peters for the contributions into experiments on the beginning stage of the project. MS acknowledges support from the Netherlands Organization for Scientific Research (Chemical Sciences, VIDI-grant No. 700.10.424) and the European Research Council (ERC-2012-StG 307760-SURFPRO).The STM data were processed with the WSXM software. ${ }^{88}$

\section{REFERENCES}

(1) Elemans, J. A. A. W.; Lei, S.; De Feyter, S. Angew. Chem. Int. Ed. 2009, 48, 7298.

(2) Klappenberger, F. Prog. Surf. Sci. 2014, 89, 1.

(3) Koepf, M.; Chérioux, F.; Wytko, J. A.; Weiss, J. Coord. Chem. Rev. 2012, 256, 2872.

(4) Müllen, K.; Rabe, J. P. Acc. Chem. Res. 2008, 41, 511.

(5) Treier, M.; Fasel, R. Chim. Int. J. Chem. 2009, 63, 122.

(6) Yokoyama, T.; Yokoyama, S.; Kamikado, T.; Okuno, Y.; Mashiko, S. Nature 2001, 413, 619.

(7) Yu, M.; Xu, W.; Kalashnyk, N.; Benjalal, Y.; Nagarajan, S.; Masini, F.; Lægsgaard, E.; Hliwa, M.; Bouju, X.; Gourdon, A.; Joachim, C.; Besenbacher, F.; Linderoth, T. R. Nano Res. 2012, 5, 903.

(8) Henningsen, N.; Rurali, R.; Limbach, C.; Drost, R.; Pascual, J. I.; Franke, K. J. J. Phys. Chem. Lett. 2011, 2, 55.

(9) Kley, C. S.; Čechal, J.; Kumagai, T.; Schramm, F.; Ruben, M.; Stepanow, S.; Kern, K. J. Am. Chem. Soc. 2012, 134, 6072.

(10) Kunkel, D. A.; Hooper, J.; Simpson, S.; Beniwal, S.; Morrow, K. L.; Smith, D. C.; Cousins, K.; Ducharme, S.; Zurek, E.; Enders, A. J. Phys. Chem. Lett. 2013, 4, 3413.

(11) Pawin, G.; Wong, K. L.; Kim, D.; Sun, D.; Bartels, L.; Hong, S.; Rahman, T. S.; Carp, R.; Marsella, M. Angew. Chem. Int. Ed. 2008, 47, 8442.

(12) Schlickum, U.; Decker, R.; Klappenberger, F.; Zoppellaro, G.; Klyatskaya, S.; Ruben, M.; Silanes, I.; Arnau, A.; Kern, K.; Brune, H.; Barth, J. V. Nano Lett. 2007, 7, 3813

(13) Shi, Z.; Lin, N. J. Am. Chem. Soc. 2010, 132, 10756.

(14) Stepanow, S.; Lin, N.; Barth, J. V. J. Phys. Condens. Matter 2008, 20, 184002.

(15) Tait, S. L.; Wang, Y.; Costantini, G.; Lin, N.; Baraldi, A.; Esch, F.; Petaccia, L.; Lizzit, S.; Kern, K. J. Am. Chem. Soc. 2008, 130, 2108

(16) Wang, Y.; Fabris, S.; Costantini, G.; Kern, K. J. Phys. Chem. C 2010, 114, 13020.

(17) Xu, W.; Wang, J.; Yu, M.; Lægsgaard, E.; Stensgaard, I.; Linderoth, T. R.; Hammer, B.; Wang, C.; Besenbacher, F. J. Am. Chem. Soc. 2010, 132, 15927.

(18) Zhang, X.; Zeng, Q.; Wang, C. Nanoscale 2013, 5, 8269. 
(19) Cheng, Z.; Luo, M.; Wyrick, J.; Sun, D.; Kim, D.; Zhu, Y.; Lu, W.; Kim, K.; Einstein, T. L.; Bartels, L. Nano Lett. 2010, 10, 3700.

(20) Kühne, D.; Klappenberger, F.; Krenner, W.; Klyatskaya, S.; Ruben, M.; Barth, J. V. Proc. Natl. Acad. Sci. 2010 107, 21332.

(21) Lei, S.; Tahara, K.; Feng, X.; Furukawa, S.; De Schryver, F. C.; Müllen, K.; Tobe, Y.; De Feyter, S. J. Am. Chem. Soc. 2008, 130, 7119.

(22) MacLeod, J. M.; Ivasenko, O.; Fu, C.; Taerum, T.; Rosei, F.; Perepichka, D. F. J. Am. Chem. Soc. 2009, 131, 16844.

(23) Ruben, M.; Payer, D.; Landa, A.; Comisso, A.; Gattinoni, C.; Lin, N.; Collin, J.-P.; Sauvage, J.-P.; De Vita, A.; Kern, K. J. Am. Chem. Soc. 2006, 128, 15644.

(24) Spillmann, H.; Kiebele, A.; Stöhr, M.; Jung, T. A.; Bonifazi, D.; Cheng, F.; Diederich, F. Adv. Mater. 2006, $18,275$.

(25) Stöhr, M.; Wahl, M.; Spillmann, H.; Gade, L. H.; Jung, T. A. Small 2007, 3, 1336.

(26) Wintjes, N.; Bonifazi, D.; Cheng, F.; Kiebele, A.; Stöhr, M.; Jung, T.; Spillmann, H.; Diederich, F. Angew. Chem. Int. Ed. 2007, 46, 4089.

(27) Björk, J.; Hanke, F. Chem. - Eur. J. 2014, 20, 928.

(28) Bartels, L. Nat. Chem. 2010, 2, 87.

(29) Grumelli, D.; Wurster, B.; Stepanow, S.; Kern, K. Nat. Commun. 2013, 4.

(30) Faraggi, M. N.; Jiang, N.; Gonzalez-Lakunza, N.; Langner, A.; Stepanow, S.; Kern, K.; Arnau, A. J. Phys. Chem. C 2012, 116, 24558.

(31) Shchyrba, A.; Nguyen, M.-T.; Wäckerlin, C.; Martens, S.; Nowakowska, S.; Ivas, T.; Roose, J.; Nijs, T.; Boz, S.; Schär, M.; Stöhr, M.; Pignedoli, C. A.; Thilgen, C.; Diederich, F.; Passerone, D.; Jung, T. A. J. Am. Chem. Soc. 2013, 135, 15270.

(32) Sirtl, T.; Schlögl, S.; Rastgoo-Lahrood, A.; Jelic, J.; Neogi, S.; Schmittel, M.; Heckl, W. M.; Reuter, K.; Lackinger, M. J. Am. Chem. Soc. 2013, 135, 691.

(33) Hanke, F.; Haq, S.; Raval, R.; Persson, M. ACS Nano 2011, 5, 9093.

(34) Saywell, A.; Greń, W.; Franc, G.; Gourdon, A.; Bouju, X.; Grill, L. J. Phys. Chem. C 2014, 118, 1719.

(35) Clair, S.; Bedwani, S.; Fabris, S.; Baroni, S.; Brune, H.; Kern, K.; Barth, J. V. J. Phys. Chem. B 2006, 110, 5627.

(36) Björk, J.; Matena, M.; Dyer, M. S.; Enache, M.; LoboCheca, J.; Gade, L. H.; Jung, T. A.; Stöhr, M.; Persson, M. Phys. Chem. Chem. Phys. 2010, 12, 8815.

(37) Lin, N.; Stepanow, S.; Vidal, F.; Kern, K.; Alam, M. S.; Strömsdörfer, S.; Dremov, V.; Müller, P.; Landa, A.; Ruben, M. Dalton Trans. 2006, 2794.

(38) Fan, Q.; Wang, C.; Han, Y.; Zhu, J.; Kuttner, J.; Hilt, G.; Gottfried, J. M. ACS Nano 2014, 8, 709.

(39) Björk, J.; Zhang, Y.-Q.; Klappenberger, F.; Barth, J. V.; Stafström, S. J. Phys. Chem. C 2014, 118 (6), 3181.

(40) Liu, X.-H.; Guan, C.-Z.; Ding, S.-Y.; Wang, W.; Yan, H.-J.; Wang, D.; Wan, L.-J. J. Am. Chem. Soc. 2013, 135, 10470.

(41) Lin, T.; Shang, X. S.; Adisoejoso, J.; Liu, P. N.; Lin, N. J. Am. Chem. Soc. 2013, 135, 3576.

(42) Li, Q.; Owens, J. R.; Han, C.; Sumpter, B. G.; Lu, W.; Bernholc, J.; Meunier, V.; Maksymovych, P.; FuentesCabrera, M.; Pan, M. Sci. Rep. 2013, 3.
(43) El Garah, M.; MacLeod, J. M.; Rosei, F. Surf. Sci. 2013, 613,6 .

(44) Lafferentz, L.; Eberhardt, V.; Dri, C.; Africh, C.; Comelli, G.; Esch, F.; Hecht, S.; Grill, L. Nat. Chem. 2012, 4, 215.

(45) Bieri, M.; Nguyen, M.-T.; Gröning, O.; Cai, J.; Treier, M.; Ait-Mansour, K.; Ruffieux, P.; Pignedoli, C. A.; Passerone, D.; Kastler, M.; Müllen, K.; Fasel, R. J. Am. Chem. Soc. 2010, 132, 16669.

(46) Gutzler, R.; Walch, H.; Eder, G.; Kloft, S.; Heckl, W. M.; Lackinger, M. Chem. Commun. 2009, 4456.

(47) Weigelt, S.; Busse, C.; Bombis, C.; Knudsen, M. M.; Gothelf, K. V.; Lægsgaard, E.; Besenbacher, F.; Linderoth, T. R. Angew. Chem. Int. Ed. 2008, 47, 4406.

(48) Matena, M.; Riehm, T.; Stöhr, M.; Jung, T. A.; Gade, L. H. Angew. Chem. Int. Ed. 2008, 47, 2414.

(49) Gourdon, A. Angew. Chem. Int. Ed. 2008, 47, 6950.

(50) Grill, L.; Dyer, M.; Lafferentz, L.; Persson, M.; Peters, M. V.; Hecht, S. Nat. Nanotechnol. 2007, 2, 687.

(51) Zhang, Y.-Q.; Kepčija, N.; Kleinschrodt, M.; Diller, K.; Fischer, S.; Papageorgiou, A. C.; Allegretti, F.; Björk, J.; Klyatskaya, S.; Klappenberger, F.; Ruben, M.; Barth, J. V. Nat. Commun. 2012, 3, 1286.

(52) Faury, T.; Dumur, F.; Clair, S.; Abel, M.; Porte, L.; Gigmes, D. CrystEngComm 2013, 15, 2067.

(53) Gao, H.-Y.; Wagner, H.; Zhong, D.; Franke, J.-H.; Studer, A.; Fuchs, H. Angew. Chem. Int. Ed. 2013, 52, 4024.

(54) Gao, H.-Y.; Franke, J.-H.; Wagner, H.; Zhong, D.; Held, P.-A.; Studer, A.; Fuchs, H. J. Phys. Chem. C 2013, 117, 18595.

(55) Schlögl, S.; Heckl, W. M.; Lackinger, M. Surf. Sci. 2012, 606, 999.

(56) Fischer, S.; Papageorgiou, A. C.; Lloyd, J. A.; Oh, S. C.; Diller, K.; Allegretti, F.; Klappenberger, F.; Seitsonen, A. P.; Reichert, J.; Barth, J. V. ACS Nano 2014, 8, 207.

(57) Marele, A. C.; Mas-Ballesté, R.; Terracciano, L.; Rodríguez-Fernández, J.; Berlanga, I.; Alexandre, S. S.; Otero, R.; Gallego, J. M.; Zamora, F.; Gómez-Rodríguez, J. M. Chem. Commun. 2012, 48, 6779.

(58) Xu, L.; Zhou, X.; Yu, Y.; Tian, W. Q.; Ma, J.; Lei, S. ACS Nano 2013, 7, 8066.

(59) Classen, T.; Fratesi, G.; Costantini, G.; Fabris, S.; Stadler, F. L.; Kim, C.; de Gironcoli, S.; Baroni, S.; Kern, K. Angew. Chem. 2005, 117, 6298.

(60) Barth, J. V.; Weckesser, J.; Lin, N.; Dmitriev, A.; Kern, K. Appl. Phys. Mater. Sci. Process. 2003, 76, 645.

(61) Stepanow, S.; Strunskus, T.; Lingenfelder, M.; Dmitriev, A.; Spillmann, H.; Lin, N.; Barth, J. V.; Wöll, C.; Kern, K. J. Phys. Chem. B 2004, 108, 19392.

(62) Abdurakhmanova, N.; Floris, A.; Tseng, T.-C.; Comisso, A.; Stepanow, S.; De Vita, A.; Kern, K. Nat. Commun. 2012, 3, 940.

(63) Dmitriev, A.; Spillmann, H.; Lin, N.; Barth, J. V.; Kern, K. Angew. Chem. Int. Ed. 2003, 42, 2670.

(64) Tseng, T.-C.; Abdurakhmanova, N.; Stepanow, S.; Kern, K. J. Phys. Chem. C 2011, 115, 10211.

(65) Stöhr, M.; Wahl, M.; Galka, C. H.; Riehm, T.; Jung, T. A.; Gade, L. H. Angew. Chem. Int. Ed. 2005, 44, 7394.

(66) Flechsig, U.; Nolting, F.; Fraile Rodríguez, A.; Krempaský, J.; Quitmann, C.; Schmidt, T.; Spielmann, 
S.; Zimoch, D.; Garrett, R.; Gentle, I.; Nugent, K.; Wilkins, S. 2010; pp. 319-322.

(67) Stöhr, J. NEXAFS spectroscopy; Springer series in surface sciences; Springer-Verlag: Berlin ; New York, 1992.

(68) Kresse, G. Phys. Rev. B 1996, 54, 11169.

(69) Blöchl, P. E. Phys. Rev. B 1994, 50, 17953.

(70) Dion, M.; Rydberg, H.; Schröder, E.; Langreth, D. C.; Lundqvist, B. I. Phys. Rev. Lett. 2004, 92.

(71) Klimeš, J.; Bowler, D. R.; Michaelides, A. J. Phys. Condens. Matter 2010, 22, 022201.

(72) Köhler, L.; Kresse, G. Phys. Rev. B 2004, 70.

(73) Fischer, S.; Papageorgiou, A. C.; Marschall, M.; Reichert, J.; Diller, K.; Klappenberger, F.; Allegretti, F.; Nefedov, A.; Wöll, C.; Barth, J. V. J. Phys. Chem. C 2012, 116, 20356.

(74) Schiffrin, A.; Reichert, J.; Pennec, Y.; Auwärter, W.; Weber-Bargioni, A.; Marschall, M.; Dell'Angela, M.; Cvetko, D.; Bavdek, G.; Cossaro, A.; Morgante, A.; Barth, J. V. J. Phys. Chem. C 2009, 113, 12101.

(75) O'Shea, J.; Luo, Y.; Schnadt, J.; Patthey, L.; Hillesheimer, H.; Krempasky, J.; Nordlund, D.; Nagasono, M.; Brühwiler, P.; Mårtensson, N. Surf. Sci. 2001, 486, 157.

(76) Kerber, S. J. J. Vac. Sci. Technol. Vac. Surf. Films 1996, 14,1314

(77) Diller, K.; Klappenberger, F.; Marschall, M.; Hermann, K.; Nefedov, A.; Woll, C.; Barth, J. V. J. Chem. Phys. 2012, 136, 014705.

(78) Piantek, M.; Miguel, J.; Krüger, A.; Navío, C.; Bernien, M.; Ball, D. K.; Hermann, K.; Kuch, W. J. Phys. Chem. C 2009, 113, 20307.

(79) Furukawa, M.; Fujisawa, H.; Katano, S.; Ogasawara, H.; Kim, Y.; Komeda, T.; Nilsson, A.; Kawai, M. Surf. Sci. 2003, 532-535, 261.

(80) Lin, Y.-P.; Ourdjini, O.; Giovanelli, L.; Clair, S.; Faury, T.; Ksari, Y.; Themlin, J.-M.; Porte, L.; Abel, M. J. Phys. Chem. C 2013, 117, 9895.

(81) Feyer, V.; Plekan, O.; Šutara, F.; Cháb, V.; Matolín, V.; Prince, K. C. Surf. Sci. 2011, 605, 361.

(82) Gahl, C.; Brete, D.; Leyssner, F.; Koch, M.; McNellis, E. R.; Mielke, J.; Carley, R.; Grill, L.; Reuter, K.; Tegeder, P.; Weinelt, M. J. Am. Chem. Soc. 2013, 135, 4273.

(83) Schmidt, R.; Hagen, S.; Brete, D.; Carley, R.; Gahl, C.; Dokić, J.; Saalfrank, P.; Hecht, S.; Tegeder, P.; Weinelt, M. Phys. Chem. Chem. Phys. 2010, 12, 4488.

(84) Brete, D.; Przyrembel, D.; Eickhoff, C.; Carley, R.; Freyer, W.; Reuter, K.; Gahl, C.; Weinelt, M. J. Phys. Condens. Matter 2012, 24, 394015.

(85) Elbing, M.; Błaszczyk, A.; von Hänisch, C.; Mayor, M.; Ferri, V.; Grave, C.; Rampi, M. A.; Pace, G.; Samorì, P.; Shaporenko, A.; Zharnikov, M. Adv. Funct. Mater. 2008, 18, 2972.

(86) Gambardella, P.; Stepanow, S.; Dmitriev, A.; Honolka, J.; de Groot, F. M. F.; Lingenfelder, M.; Gupta, S. S.; Sarma, D. D.; Bencok, P.; Stanescu, S.; Clair, S.; Pons, S.; Lin, N.; Seitsonen, A. P.; Brune, H.; Barth, J. V.; Kern, K. Nat. Mater. 2009, 8, 189.

(87) Lin, N.; Dmitriev, A.; Weckesser, J.; Barth, J. V.; Kern, K. Angew. Chem. Int. Ed. 2002, 41, 4779.
Horcas, I.; Fernández, R.; Gómez-Rodríguez, J. M.; Colchero, J.; Gómez-Herrero, J.; Baro, A. M. Rev. Sci. Instrum. 2007, 78, 013705. 
